\title{
Perspectives of hospital emergency department staff on trauma- informed care for injured children: An Australian and New Zealand analysis
}

\author{
Claire Hoysted, ${ }^{1}$ Franz E Babl, $, 3,3,4,5$ Nancy Kassam-Adams, ${ }^{6,7}$ Markus A Landolt, ${ }^{8,9}$ Laura Jobson, ${ }^{1}$ Sarah Curtis, ${ }^{10,11}$ \\ Anupam B Kharbanda, ${ }^{12,13}$ Mark D Lyttle, ${ }^{14,15,16}$ Niccolò Parri, ${ }^{17,18}$ Rachel Stanley ${ }^{19,20}$ and Eva Alisic ${ }^{3,8,21}$ \\ ${ }^{1}$ School of Psychological Sciences, and ${ }^{21}$ Monash University Accident Research Centre, Monash University, ${ }^{2}$ Emergency Department, Royal Children's \\ Hospital, ${ }^{3}$ Emergency Research, Murdoch Children's Research Institute, ${ }^{4}$ Department of Paediatrics, University of Melbourne, Melbourne, Victoria, \\ Australia, ${ }^{5}$ Paediatric Research in Emergency Departments International Collaborative (PREDICT) and the Pediatric Emergency Research Networks (PERN), \\ ${ }^{11}$ Pediatric Emergency Research Canada (PERC), ${ }^{13}$ Pediatric Emergency Medicine Collaborative Research Committee of the American Academy of \\ Pediatrics (PEMCRC), ${ }^{15}$ Paediatric Emergency Research in the United Kingdom and Ireland (PERUKI), ${ }^{18}$ Research in European Pediatric Emergency Medicine \\ (REPEM), ${ }^{20}$ Pediatric Emergency Care Applied Research Network (PECARN), ${ }^{6}$ Center for Injury Research and Prevention, Children's Hospital of Philadelphia, \\ ${ }^{7}$ University of Pennsylvania, Philadelphia, Pennsylvania, ${ }^{12}$ Department of Pediatric Emergency Medicine, Children's Hospitals and Clinics of Minnesota, \\ Minneapolis, Minnesota, ${ }^{19}$ Department of Emergency Medicine, University of Michigan, Ann Arbor, Michigan, United States, ${ }^{8}$ Department of \\ Psychosomatics and Psychiatry, University Children's Hospital Zurich, 'Division of Child and Adolescent Health Psychology, Department of Psychology, \\ University of Zurich, Zurich, Switzerland, ${ }^{10}$ Department of Pediatrics and Emergency Medicine, Women and Children's Health Research Institute, University \\ of Alberta, Edmonton, Alberta, Canada, ${ }^{14}$ Emergency Department, Bristol Royal Hospital for Children, ${ }^{16}$ Faculty of Health and Applied Science, University of \\ the West of England, Bristol, United Kingdom and ${ }^{17}$ Department of Emergency Medicine and Trauma Center, Meyer University Children's Hospital, \\ Florence, Italy
}

\begin{abstract}
Aim: To examine Australian and New Zealand emergency department (ED) staff's training, knowledge and confidence regarding trauma-informed care for children after trauma, and barriers to implementation.

Methods: ED staff's perspectives on trauma-informed care were assessed using a web-based self-report questionnaire. Participants included 468 ED staff (375 nursing and 111 medical staff) from hospitals in Australia and New Zealand. Data analyses included descriptive statistics, $\chi^{2}$ tests and multiple regressions.

Results: Over $90 \%$ of respondents had not received training in trauma-informed care and almost all respondents (94\%) wanted training in this area. While knowledge was associated with a respondent's previous training and profession, confidence was associated with the respondent's previous training, experience level and workplace. Dominant barriers to the implementation of trauma-informed care were lack of time and lack of training. Conclusions: There is a need and desire for training and education of Australian and New Zealand ED staff in trauma-informed care. This study demonstrates that experience alone is not sufficient for the development of knowledge of paediatric traumatic stress reactions and traumainformed care practices. Existing education materials could be adapted for use in the ED and to accommodate the training preferences of Australian and New Zealand ED staff.
\end{abstract}

Key words: child; emergency service, hospital; mental health; paediatrics; stress disorders, post-traumatic.

What is already known on this topic

1 Approximately $15 \%$ of injured children develop persistent stress symptoms that impair functioning and development.

2 Emergency department (ED) staff are in a key position to help prevent persistent stress in injured children.

3 There is a lack of understanding and training in this area among ED staff worldwide.

\section{What this paper adds}

1 This study of Australian and New Zealand ED staff demonstrates that there is a need and desire for training in persistent stress reactions and psychosocial aspects of acute health care in this region.

2 Additionally, this study shows that experience alone is not sufficient for the development of knowledge of persistent stress reactions following a paediatric injury.

3 The responses suggest specific topics of this education, such as the child's experience of pain increasing the risk of persistent stress reactions.
Correspondence: Ms Claire Hoysted, Monash University Accident Research Centre (c/o Eva Alisic), Monash University, Melbourne, Vic. 3800, Australia. Fax: +6139905 4363; email: claire.hoysted@monash.edu Conflict of interest: None declared.

Accepted for publication 22 February 2017.
In Australia and New Zealand, injury is one of the leading causes of hospitalised morbidity, ${ }^{1}$ with over 100000 children presenting to emergency departments (EDs) with injuries each year. ${ }^{2,3}$ Childhood injuries can have profound and lifelong effects, including permanent physical disabilities and long-term cognitive or psychological difficulties. ${ }^{4}$ Post-traumatic stress (PTS) is a 
common psychological response after a childhood injury and can include symptoms such as intrusive thoughts, sleep problems and concentration difficulties. ${ }^{5-7}$ PTS symptoms are distressing to the child and family and can result in impairment of functioning and delay the development of cognitive, social and emotional abilities. ${ }^{6-9}$ The initial period following the injury is a critical window for the prevention or intervention of later PTS. ${ }^{10}$ As such, paediatric ED staff have been recognised as having an important role in the prevention and management of PTS. ${ }^{11,12}$

Despite recognition of the impact of PTS, Australian paediatric emergency care clinicians report a lack of adequate psychosocial support provided to injured children and their families in EDs. ${ }^{1}$

To address this, researchers and clinicians have described the importance of providing 'trauma-informed care' in paediatric ED settings as a preventive approach to minimise the impact of emotional trauma. ${ }^{12}$ Throughout this paper, 'trauma' refers to emotional trauma that may result from the accident, injury, illness or medical treatment, not physical injury. Trauma-informed care, as defined by the Substance Abuse and Mental Health Services Administration (SAMHSA), refers to the way in which organisations, and in this case ED staff and paediatric health-care systems, can prevent or minimise emotional trauma. ${ }^{13}$ Specifically, a trauma-informed care approach in an organisation involves: understanding the widespread impact of trauma; being aware of the signs and symptoms of trauma in clients, families and staff; incorporating a knowledge of trauma into policies and procedures; and aiming to prevent further trauma. ${ }^{13}$

The provision of trauma-informed care in paediatric EDs minimises the risk of PTS, assists in managing the distress of injured children and their families, provides emotional support and promotes children's mental and physical recovery. ${ }^{12,14,15}$ Training in trauma-informed ED care may help improve outcomes for children. ${ }^{12,14}$ Prior to implementing training programmes, it is important to establish ED staff's current level of knowledge of traumainformed care, their attitudes towards trauma-informed care and preferences for training in order to target the specific gaps in knowledge and meet the needs of the population. Previous research has examined ED staff practices and perspectives on trauma-informed care in hospitals in the USA ${ }^{16-18}$ and in an international population, ${ }^{19}$ indicating there is a lack of knowledge of psychological difficulties experienced by children following injuries and a lack of skills in promoting psychological recovery. However, the descriptions of international data provide little specific insight regarding levels of training or knowledge in traumainformed care in Australia and New Zealand. The health-care systems in Australia and New Zealand differ from many of their international counterparts in the structure of training ${ }^{20}$ and emergency care services, ${ }^{21}$ the provision of publicly funded medical care, profile of paediatric injuries ${ }^{1,21,22}$ and the geographical challenges of a dispersed population. ${ }^{21}$ These characteristics of the EDs in Australia and New Zealand suggest that levels of training and training needs of staff in this region may differ from countries such as the USA.

The aim of the current study was to examine the perspectives of Australian and New Zealand ED staff on trauma-informed care. In particular, we aimed to understand: (i) what proportion of ED staff have received training in trauma-informed care and their training preferences; (ii) ED staff's knowledge of PTS in children; (iii) ED staff's confidence in providing trauma-informed care; and (iv) what barriers to implementing trauma-informed care are experienced by ED staff.

\section{Methods \\ Design}

The data used in this study were extracted from a larger international data set for which data collection and study design procedures have been previously described. ${ }^{19}$ The Human Research Ethics Committee of the Royal Children's Hospital Melbourne approved the study (HREC 33085).

\section{Survey development and administration}

ED staff's perspectives on trauma-informed care were assessed with a web-based self-report questionnaire, available from the authors or via the Trauma Recovery website. ${ }^{22}$ This self-report questionnaire $^{19}$ examined knowledge of PTS, confidence in providing trauma-informed care, whether the participant has had specific training in trauma-informed care and training preferences.

\section{Study population}

Respondents were recruited via the Paediatric Emergency Departments International Collaborative ${ }^{23}$ (PREDICT) and Pediatric Emergency Research Networks ${ }^{24}$ (PERN), the College of Emergency Nursing Australasia and the College of Emergency Nursing New Zealand. A snowball approach to recruitment was utilised to obtain as many responses as possible from staff in areas with less participation in professional organisations; as such, we are unable to determine a response rate.

\section{Data analyses}

Data were exported from SurveyMonkey and analysed using SPSS version 21 (IBM, Armonk, NY, USA). Values of $P<0.05$ were considered to be statistically significant. We calculated total scores for knowledge of PTS and confidence in providing traumainformed care (full details have been previously described ${ }^{19}$ ). An a priori independent $t$-test was conducted to confirm that separate analysis of Australian and New Zealand ED staff was warranted from the international sample (see Appendix S1, Supporting Information). ${ }^{19}$ We then conducted an a priori analysis of equivalence, which determined that it was appropriate to combine responses from Australia and New Zealand (see Appendix S1, Supporting Information).

We used descriptive statistics to describe respondent characteristics, knowledge, training status and preferences and barriers to implementing trauma-informed care. Multiple regression analyses were conducted to predict knowledge and confidence scores using profession (nursing, medical staff), years of experience, training in trauma-informed care and department (paediatric ED, combined ED, adult ED) as the predictors. Finally, we conducted $\chi^{2}$ analyses to compare specific elements of medical and nursing staff's knowledge of PTS and confidence in providing traumainformed care. 
Table 1 Characteristics of survey respondents

\begin{tabular}{|c|c|c|c|}
\hline & \multicolumn{2}{|c|}{ By profession } & \multirow[t]{2}{*}{ Total sample $(n=486)$} \\
\hline & Nursing $(n=375)$ & Medical $(n=111)$ & \\
\hline \multicolumn{4}{|l|}{ Age } \\
\hline Mean (SD) & $43.06(11.13)$ & $37.58(7.50)$ & $41.81(10.66)$ \\
\hline \multicolumn{4}{|l|}{ Gender, $n(\%)$} \\
\hline Female & $333(88.80)$ & $56(50.45)$ & $389(80.00)$ \\
\hline \multicolumn{4}{|l|}{ Country, $n(\%)$} \\
\hline Australia & $152(40.53)$ & $100(90.09)$ & $252(51.53)$ \\
\hline New Zealand & $223(59.47)$ & $11(9.91)$ & $234(48.47)$ \\
\hline \multicolumn{4}{|l|}{ Location, $n(\%)$} \\
\hline Rural area & $78(20.8)$ & $5(4.50)$ & $83(17.08)$ \\
\hline Suburban area & $80(21.33)$ & $22(19.82)$ & $102(20.99)$ \\
\hline Urban area & $217(57.87)$ & $84(75.68)$ & $301(61.93)$ \\
\hline \multicolumn{4}{|l|}{ Department, $n(\%)$} \\
\hline Paediatric ED & $93(24.80)$ & $63(56.76)$ & $156(32.10)$ \\
\hline Combined paediatric and adult ED & $243(64.80)$ & $41(36.94)$ & $284(58.43)$ \\
\hline Adult ED & $39(10.40)$ & $7(6.31)$ & $46(9.47)$ \\
\hline \multicolumn{4}{|l|}{ Years of experience in patient care } \\
\hline Mean (SD) & $19.92(12.09)$ & $13.60(8.00)$ & $18.48(11.59)$ \\
\hline \multicolumn{4}{|c|}{ Previous training in trauma-informed care, $n(\%)$} \\
\hline No training & $343(91.47)$ & $101(90.99)$ & $444(91.36)$ \\
\hline Have had training & $32(8.53)$ & $10(9.01)$ & $42(8.64)$ \\
\hline \multicolumn{4}{|c|}{ Further training in trauma-informed care, $n(\%)$} \\
\hline Want training & $359(95.22)$ & $98(88.28)$ & $457(94.00)$ \\
\hline Do not want training & $7(4.78)$ & $13(11.17)$ & $29(7.00)$ \\
\hline
\end{tabular}

ED, emergency department; SD, standard deviation.

\section{Results}

The sample consisted of 468 ED staff (375 nursing staff and 111 medical staff ) who were recruited from hospitals in Australia and New Zealand. Characteristics of the survey respondents are presented in Table 1.

\section{Training status and preferences}

Over $90 \%$ of Australian and New Zealand ED staff had no training in trauma-informed care. Almost all respondents (94\%) indicated a desire for training in trauma-informed care. Of the respondents interested in training, $46 \%$ indicated they would be able to commit $1-4 \mathrm{~h}$ to training in the next 6 months, $31 \%$ would commit 5-8 h, and $23 \%$ could commit more than $8 \mathrm{~h}$. Most preferred in-person group training, in a single block, followed by an interactive website (see Table 2 ).

\section{Knowledge of post-traumatic stress}

ED staff demonstrated varying levels of knowledge across the areas examined (see Table 3). For example, the majority of ED staff $(86.6 \%)$ could correctly identify that an injured child, his or her siblings and parents are all at risk of PTS. However, only $2.8 \%$ of ED staff could correctly identify the prevalence of children who develop one or more symptoms of PTS in the first month following the injury of PTS. Compared to nursing staff, significantly more medical staff were aware that a child's pain severity and his or her perception of threats to life both increase the risk for PTS.

The regression analyses showed that the combination of all variables significantly predicted knowledge of trauma-informed

Table 2 Australian and New Zealand ED staff's training preferences $(n=457)$

\begin{tabular}{lcc}
\hline & $\begin{array}{c}\text { First } \\
\text { preference (\%) }\end{array}$ & $\begin{array}{c}\text { Second } \\
\text { preference (\%) }\end{array}$ \\
\hline $\begin{array}{l}\text { Group training in-person in one } \\
\text { block of hours }\end{array}$ & 30 & 23 \\
$\begin{array}{l}\text { Online: Interactive website } \\
\text { (e.g. webinar, video examples, } \\
\quad \text { quizzes) }\end{array}$ & 24 & 21 \\
$\begin{array}{l}\text { Online: Website and written } \\
\text { information }\end{array}$ & 17 & 17 \\
$\begin{array}{l}\text { Group training in-person spread } \\
\text { over a number of weeks }\end{array}$ & 12 & 14 \\
$\begin{array}{l}\text { Individual mentor sessions with an } \\
\text { experienced clinician of my own } \\
\text { profession }\end{array}$ & 8 & 8 \\
$\begin{array}{l}\text { A book on the topic } \\
\text { Individual mentor sessions with a } \\
\text { mental health clinician }\end{array}$ & 3 & 10 \\
\hline
\end{tabular}

All ED staff who indicated they want training in trauma-informed care. $E D$, emergency department. 
Table 3 Australian and New Zealand ED staff's knowledge of paediatric PTS, correct answers, $n$ (\%)

\begin{tabular}{|c|c|c|c|c|c|}
\hline \multirow[t]{2}{*}{ Statement } & \multirow[t]{2}{*}{ Total sample $(n=486)$} & \multicolumn{2}{|c|}{ By profession } & \multirow[t]{2}{*}{$P$ value } & \multirow[t]{2}{*}{ V } \\
\hline & & Nurses $(n=375)$ & Medical $(n=111)$ & & \\
\hline All levels of injury severities are at risk for traumatic stress & $327(67.2)$ & $252(67.2)$ & $75(67.5)$ & 0.94 & NA \\
\hline All age groups are at risk for traumatic stress & $249(51.2)$ & $195(52.0)$ & $54(48.6)$ & 0.54 & NA \\
\hline Child/Parents/Siblings are at risk & $421(86.6)$ & $321(85.6)$ & $100(90)$ & 0.22 & NA \\
\hline Various behaviours (e.g. calm, frantic) can indicate risk & $194(39.9)$ & $141(37.6)$ & $53(47.7)$ & 0.06 & NA \\
\hline Subjective life threat is risk factor & $306(62.9)$ & $209(55.7)$ & $97(87.3)$ & $<0.00 *$ & 0.275 \\
\hline Pain is a risk factor & $172(35.3)$ & $114(30.4)$ & $58(52.2)$ & $<0.00 *$ & 0.192 \\
\hline$>50 \%$ of children report stress symptoms in first month post-injury & $14(2.8)$ & $10(2.6)$ & $4(3.6)$ & 0.60 & NA \\
\hline
\end{tabular}

$* P<0.05 . V=$ Cramer's $V ; D F=2 ; 0.07=$ small effect; $0.21=$ moderate effect; 0.35 = large effect. Responses were coded as correct/incorrect. $P$ values and Cramer's $V$ statistics are related to a $\chi^{2}$ analysis of the difference in knowledge of PTS between medical and nursing staff. ED, emergency department; NA, not applicable; PTS, post-traumatic stress.

care and explained $5 \%$ of the variance in the model. The variables 'profession' and 'training' uniquely predicted knowledge scores (see Table 4), indicating that higher levels of knowledge were associated with being a physician and being trained in trauma-informed care. Years of experience did not predict knowledge of trauma-informed care.

\section{Confidence in providing trauma-informed care}

Table 5 shows the mean confidence score for each element of trauma-informed care, with highest scores 3.76 and lowest scores of 2.45. Respondents were most confident about explaining

Table 4 Multiple regression analysis of ED staff's knowledge of PTS and ED staff's confidence in providing trauma-informed care

ED staff's knowledge of PTS $(n=486)$

\begin{tabular}{lccl}
\hline Variable & $B$ & SEB & $\beta$ \\
\hline Profession (nurse, physician) & 0.66 & 0.16 & $0.19 *$ \\
Department (adult ED, paediatric ED) & 0.17 & 0.15 & 0.09 \\
Years of experience in patient care & 0.01 & 0.01 & 0.06 \\
$\begin{array}{l}\text { Training in trauma-informed care (no training, } \\
\quad\end{array}$ & 0.48 & 0.24 & $0.09 *$ \\
$\quad$ had training) & & & \\
\hline
\end{tabular}

ED staff's confidence in providing trauma-informed care

\begin{tabular}{lrrr}
\hline Variable & $B$ & SEB & \multicolumn{1}{c}{$\beta$} \\
\hline Profession (nurse, physician) & -0.70 & 0.85 & -0.04 \\
Department (adult ED, paediatric ED) & 3.00 & 0.79 & $0.18^{*}$ \\
Years of experience in patient care & 0.12 & 0.03 & $0.18^{*}$ \\
Training in trauma-informed care & 4.30 & 1.22 & $0.17^{*}$ \\
$\quad$ (no training, had training) & & & \\
\hline
\end{tabular}

$* P<0.05 ; F(4,481)=6.46, P<0.00, R^{2}=0.05$. Nurse, adult ED and no training were coded ' $O$ '. Physician paediatric ED and have had training were coded ' 1 '. ED staff's confidence in providing trauma-informed care: $n=486 . * P<0.005 ; F(4,481)=10.78, P<0.00, R^{2}=0.08$. $\beta$, standardised coefficient; $B$, unstandardised regression coefficient; ED, emergency department; PTS, post-traumatic stress; SEB, standard error of the coefficient. procedures to children and parents and mobilising professional and social support for the child. Respondents were least confident in identifying those at risk and educating children and families about PTS reactions and accessing help. A $\chi^{2}$ test was conducted to examine differences in confidence in trauma-informed care between professions (see Table 5). Compared to medical staff, nurses reported significantly higher degrees of confidence in helping children or parents to calm down by teaching relaxation, arranging for a support person to be available to the child, encouraging parents to mobilise their own support network and tailoring their approach to the families' culture or background. In contrast, medical staff reported significantly higher degrees of confidence in informing children about an injured or deceased family member and responding to children's or parents' questions about whether the child will die.

The regression analyses showed that the combination of all variables significantly predicted confidence in providing traumainformed care and explained $8 \%$ of the variance in the model. The variables 'experience', 'department' and 'training' uniquely predicted confidence scores, demonstrating that higher confidence was associated with working in a paediatric ED, being trained in trauma-informed care and having more years of experience, albeit with small effects (see Table 4).

\section{Barriers to implementing trauma-informed care}

The barriers to implementing trauma-informed care experienced by ED staff are displayed in Figure 1. Over $90 \%$ of respondents indicated that the issue of time constraint was a barrier to implementing trauma-informed care. This was closely followed by a lack of training; $90 \%$ of respondents identified a lack of training as a barrier to implementing trauma-informed care.

\section{Discussion}

This study suggests that very few ED staff in Australia and New Zealand have received training in trauma-informed care. With the growing understanding of the impact of PTS and the benefits of trauma-informed care, ${ }^{7,12,25-27}$ this represents an area for improvement in the education of future ED staff and for the professional development of the current workforce. The vast 
Table 5 Australian and New Zealand ED staff's confidence in providing trauma-informed care; mean (standard deviation) (four-point Likert-type scale)

\begin{tabular}{|c|c|c|c|c|c|}
\hline \multirow[t]{2}{*}{ Statement } & \multirow{2}{*}{$\begin{array}{c}\text { Total } \\
\text { sample }(n=486)\end{array}$} & \multicolumn{2}{|c|}{ By profession } & \multirow{2}{*}{$\begin{array}{c}P \\
\text { value }\end{array}$} & \multirow[t]{2}{*}{ V } \\
\hline & & $\begin{array}{l}\text { Nurses } \\
(n=375)\end{array}$ & $\begin{array}{l}\text { Medical } \\
(n=111)\end{array}$ & & \\
\hline $\begin{array}{l}\text { Respond calmly and without judgment to a child's or family's strong emotional } \\
\text { distress }\end{array}$ & $3.57(0.54)$ & $3.58(0.29)$ & $3.51(0.05)$ & 0.16 & NA \\
\hline Talk with children in age appropriate language & $3.68(0.53)$ & $3.69(0.02)$ & $3.66(0.05)$ & 0.45 & NA \\
\hline Tailor your approach according to a family's cultural background & $3.29(0.63)$ & $3.30(0.03)$ & $3.25(0.05)$ & $0.02 *$ & 0.13 \\
\hline Assess and manage pain in children & $3.57(0.56)$ & $3.56(0.03)$ & $3.66(0.5)$ & 0.21 & NA \\
\hline Explain procedures to children and parents & $3.76(0.45)$ & $3.73(0.02)$ & $3.73(0.4)$ & 0.34 & NA \\
\hline Inform a child about an injured/deceased family member & $2.65(0.84)$ & $2.59(0.04)$ & $2.84(0.7)$ & $0.05 *$ & 0.13 \\
\hline Help a child/parent who is anxious to calm down by teaching relaxation & $3.09(0.75)$ & $3.18(0.38)$ & $2.78(0.07)$ & $<0.00^{*}$ & 0.22 \\
\hline Assess a child's or family's distress, emotional needs and support systems & $3.19(0.70)$ & $3.21(0.03)$ & $3.15(0.06)$ & 0.26 & NA \\
\hline $\begin{array}{l}\text { Elicit trauma details from a child or family without them being exposed to more } \\
\text { distress }\end{array}$ & $2.83(0.74)$ & $2.81(0.03)$ & $2.87(0.07)$ & 0.34 & NA \\
\hline Respond to a child's or parent's question about whether the child will die & $2.83(0.81)$ & $2.79(0.04)$ & $2.96(0.08)$ & $<0.00 *$ & 0.16 \\
\hline Liaise with staff who can provide practical assistance to a family (e.g. social work) & $3.70(0.52)$ & $3.71(0.02)$ & $3.65(0.05)$ & 0.56 & NA \\
\hline $\begin{array}{l}\text { Take action to get someone close (a parent, family member or friend) available to the } \\
\text { child in the ED }\end{array}$ & $3.72(0.50)$ & $3.76(0.02)$ & $3.57(0.05)$ & $<0.00 *$ & 0.20 \\
\hline $\begin{array}{l}\text { Encourage parents to make use of their own social support system (family, friends, } \\
\text { spiritual community, and so on) }\end{array}$ & $3.48(0.60)$ & $3.52(0.03)$ & $3.33(0.06)$ & $0.02 *$ & 0.13 \\
\hline Educate children and families about common traumatic stress reactions & $2.47(0.82)$ & $2.47(0.04)$ & $2.52(0.07)$ & 0.27 & NA \\
\hline Teach parents or children specific ways to cope with procedures in the ED & $3.11(0.72)$ & $3.13(0.03)$ & $3.06(0.06)$ & 0.899 & NA \\
\hline $\begin{array}{l}\text { Provide information to parents about emotional or behavioural reactions that } \\
\text { indicate that the child may need help (when back at home) }\end{array}$ & $2.45(0.88)$ & $2.46(0.04)$ & $2.45(0.07)$ & 0.365 & NA \\
\hline Educate parents or children about how to access mental health services if needed & $2.79(0.83)$ & $2.78(0.04)$ & $2.88(0.07)$ & 0.209 & NA \\
\hline Manage your own emotional responses to children's pain and trauma & $3.37(0.62)$ & $3.40(0.03)$ & $3.33(0.06)$ & 0.52 & NA \\
\hline
\end{tabular}

$* P<0.05 . V=$ Cramer's $V ; D F=2 ; 0.07=$ small effect; $0.21=$ moderate effect; $0.35=$ large effect. Items were measured on a Likert-type scale $\left(1=\right.$ not at all confident, 2 = a little confident, $3=$ moderately confident, $4=$ very confident). $P$ values and Cramer's $V$ statistics relate to a $\chi^{2}$ analysis of the difference in confidence in providing trauma-informed care between medical and nursing staff. ED, emergency department; NA, not applicable.

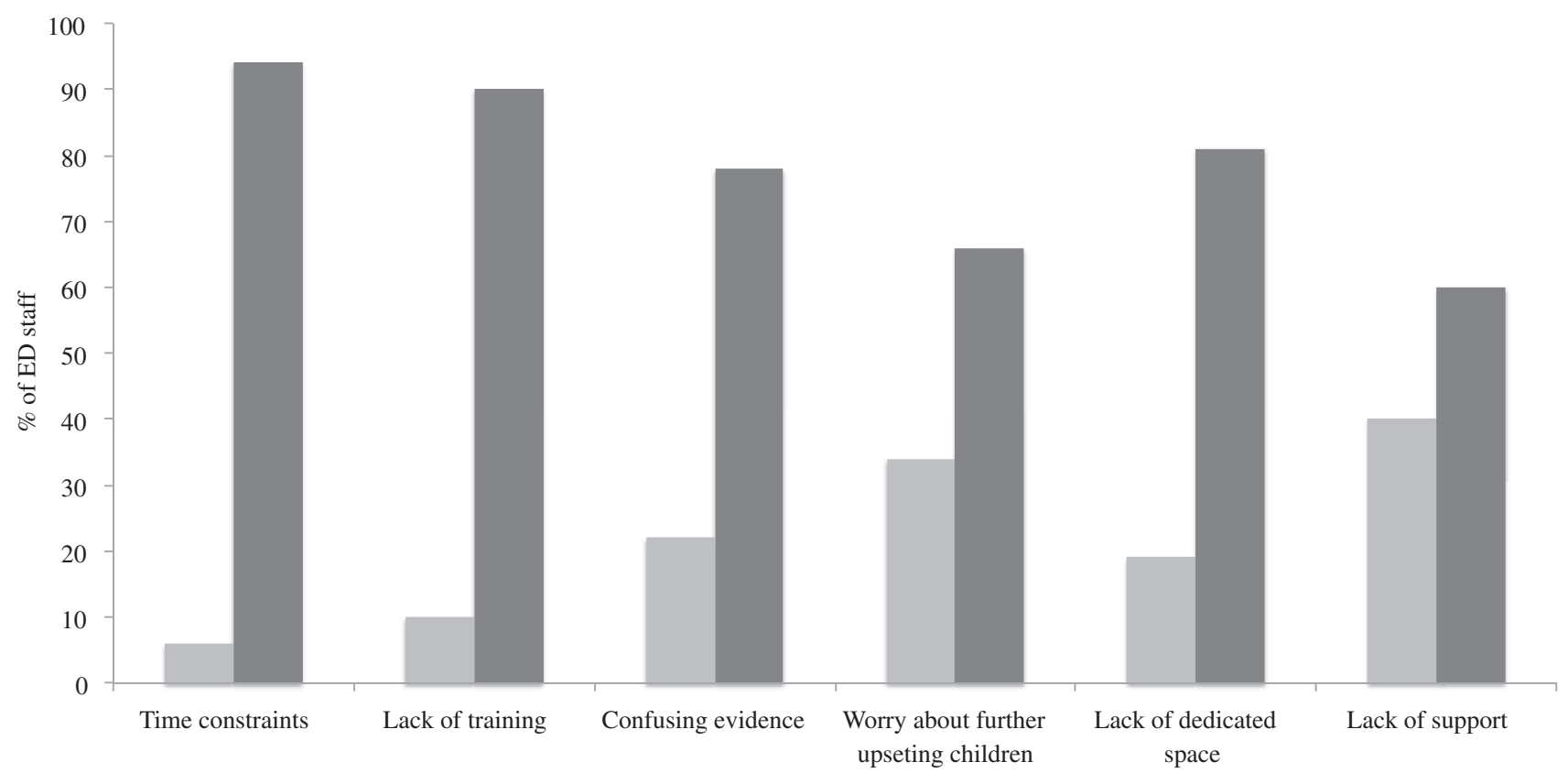

Barriers to implementing trauma-informed care

Fig. 1 Barriers to implementing trauma-informed care. ( ), Not considered a barrier; $(\square)$, considered a barrier. 
majority of respondents expressed a desire for training in trauma-informed care and reported they could dedicate time to such training. The common element of the preferred training modalities is an interactive and applied approach to learning. Therefore, training programmes for trauma-informed care should be developed to meet the preferences of ED staff in this region.

In this analysis, ED staff from Australia and New Zealand demonstrated varied knowledge of paediatric PTS reactions. While insight about the risk for family members was strong, weaknesses were identified in recognising behaviours that can indicate risk and distress and the relationship between the child's pain rating and his or her risk of PTS. Additionally, the results suggest that ED staff may lack awareness of the prevalence of psychological difficulties experienced by children exposed to an injury, ${ }^{16,18}$ which may provide some explanation for a lack of awareness of tools for assessing PTS ${ }^{16,27}$ and PTS symptoms. It is possible that this lack of awareness contributes to the comparatively lower levels of confidence found in these skills. Greater knowledge was associated with having had specific training in trauma-informed or psychosocial care. Of note, there was no relationship between years of experience or experience in a paediatric ED and knowledge of children's PTS reactions. This suggests that knowledge of children's PTS reactions does not develop with experience alone, further strengthening the argument for the need of widely distributed training in this region.

The majority of ED staff feel moderately confident in implementing aspects of trauma-informed care. Training in traumainformed care, working in a paediatric ED and more years of experience were associated with more confidence in these skills. The common theme underpinning the skills associated with less confidence (educating children and families about trauma reactions and how to identify those at risk and access help) is that they are directly related to applying specific knowledge and understanding of PTS and trauma-informed approaches to care, whereas the skills associated with greater confidence (explaining procedures to children and parents and mobilising professional and social support for the child) can be adapted from other models of care practiced in EDs in Australia and New Zealand, such as procedural pain management, family-centred care and practitioner self-care. This suggests that training could focus on the areas of low confidence and support and reinforce the relevant areas of perceived competence. Differences across aspects of confidence in trauma-informed care varied between medical and nursing staff and reflected the differing roles between the professions in this region. For example, nurses may lead in engaging the child or family in relaxation techniques, whereas a physician's role would involve discussing prognosis. Profession-specific roles should be taken into account when developing training in this area.

The current study demonstrated some associations between demographic variables and knowledge and confidence scores; however, the small effect sizes suggest that there is no justification to target a particular group of ED staff in Australia and New Zealand. Rather, the lack of difference in knowledge and confidence levels across groups indicates that training and education in trauma-informed care is needed across the workforce. Existing education programmes that might address the confidence and competence needs of ED staff include psychological first aid (PFA) training, ${ }^{28,29}$ resources from the HealthCare
Toolbox website ${ }^{30}$ and the Trauma Toolbox for Primary Care. ${ }^{31}$ Both the PFA training programme and Health Care Toolbox include interactive elements providing opportunities for ED staff to apply the knowledge and skills developed and receive feedback. This format meets the preference for brief interactive elearning identified by ED staff in this region. In the evaluation and development of training in this area, preferences for brief training must be balanced with ensuring that ED staff are able to retain and incorporate the knowledge and skills learnt into their practice. ${ }^{32}$ Further research is required to examine the efficacy and feasibility of available training programmes to support calls for widespread training in trauma-informed care. ${ }^{12}$

In addition to addressing the confidence and competence needs of Australian and New Zealand ED staff, education programmes and policy must consider the barriers that ED staff experience in implementing trauma-informed care. Almost all ED staff felt that time constraints and a lack of training were barriers to the implementation of trauma-informed care. Perceived time pressures have been previously identified as a source of stress for ED staff in this region. ${ }^{33,34}$ Training programmes developed for Australian and New Zealand ED staff should aim to increase knowledge and skills in providing care in a traumainformed way without increasing pressure on time and should provide clarity on the evidence for best practice. ${ }^{12,33}$

\section{Limitations}

Several limitations of the study need to be taken into account. This study examined staff's knowledge and confidence regarding trauma-informed care; however, it did not provide information on the ability of respondents or the quality of trauma-informed care delivered by the respondents (respondents did have the option to indicate if they felt trauma-informed care was or was not part of their role). Furthermore, the use of self-report measures may have resulted in self-report biases, such as respondents portraying themselves positively, confounding the data. Due to the recruitment approach, response rates could not be calculated. Additionally, as participation was necessarily voluntary, respondents may have been more likely to express an interest in trauma-informed care, and although explicitly invited, it is possible that staff with negative views or limited knowledge in this area were not well represented.

\section{Conclusions}

This study demonstrates that Australian and New Zealand ED staff have limited knowledge and confidence in the care of PTS in injured children. Very few clinical ED staff have received any training on PTS or trauma-informed care. Training in traumainformed care should be seen as an essential component of education programmes in emergency nursing or medical training. Importantly, this study demonstrates that experience alone is not sufficient in the development of knowledge of PTS and traumainformed care practices, suggesting the need for widespread training in the current workforce. Additionally, there is very little variation in knowledge of PTS reactions and confidence in traumainformed care across demographic and organisational characteristics, indicating that a universal approach to training can be used 
for ED staff interested in developing their knowledge and skills in this area.

\section{Acknowledgements}

We thank the many organisations and individuals who have contributed to the development and distribution of the survey. The organisations include, but are not limited to, the Pediatric Emergency Research Networks (PERN), the Paediatric Research in Emergency Departments International Collaborative (PREDICT), the College of Emergency Nursing Australasia (CENA) and the College of Emergency Nurses New Zealand (CENNZ). Additionally, we thank Dr Kate Taylor (School of Psychological Science, Monash University, Melbourne, Australia) and Dr Audrey McKinlay (Melbourne School of Psychological Sciences, The University of Melbourne, Melbourne, Australia) for their assistance in the design stage of this study.

C Hoysted was funded by an Australian Government Research Training Program (PTP) Scholarship. E Alisic was funded by an Early Career Fellowship (\#1090229), National Health and Medical Research Council, Australia. FE Babl was funded by Centre of Research Excellence for Paediatric Emergency Medicine, National Health and Medical Research Council, Australia; Victorian Government's Infrastructure Support Program, Melbourne, Australia and Royal Children's Hospital Foundation, Melbourne, Australia. R Stanley and PECARN are funded by Health Resources and Services Administration (HRSA), Maternal and Child Health Bureau (MCHB), Emergency Medical Services for Children (EMSC) Network Development Demonstration Program under cooperative agreement number U03MC00008 and MCHB cooperative agreements U03MC00001, U03MC00003, U03MC00006, U03MC00007, U03MC22684 and U03MC22685. This information or content and conclusions are those of the author and should not be construed as the official position or policy of, nor should any endorsements be inferred by HRSA, HHS or the U.S. Government. The funding sources had no role in the design and conduct of the study; collection, management, analysis and interpretation of the data; preparation, review or approval of the manuscript; and decision to submit the manuscript for publication.

\section{References}

1 Curtis K, Caldwell E, Delprado A, Munroe B. Traumatic injury in Australia and New Zealand. Australas. Emerg. Nurs. J. 2012; 15: 45-54.

2 Safekids Aotearoa. Child Injury Profile: 2008-2012 (Hospital Admissions, Age 0-14). Auckland: Safekids Aotearoa, 2014.

3 Australian Institute of Health and Welfare. Trends in Hospitalised Injury, Australia: 1999-00 to 2012-13. Canberra: The Institute, 2015. Injury Research and Statistics Series No.: 95. Cat. No.: INJCAT 171.

4 Meiser-Stedman R, Smith P, Glucksman E, Yule W, Dalgleish T. The posttraumatic stress disorder diagnosis in preschool-and elementary school-age children exposed to motor vehicle accidents. Am. J. Psychiatry 2008; 165: 1326-37.

5 Kassam-Adams N, Felipe García-España J, Marsac ML et al. A pilot randomized controlled trial assessing secondary prevention of traumatic stress integrated into pediatric trauma care. J. Trauma Stress 2011; 24: 252-9.

6 Zatzick DF, Jurkovich GJ, Fan M-Y et al. Association between posttraumatic stress and depressive symptoms and functional outcomes in adolescents followed up longitudinally after injury hospitalization. JAMA Pediatr. 2008; 162: 642-8.
7 Kassam-Adams N, Marsac ML, Hildenbrand A, Winston F. Posttraumatic stress following pediatric injury: Update on diagnosis, risk factors, and intervention. JAMA Pediatr. 2013; 167: 1158-65.

8 Landolt MA, Vollrath ME, Gnehm HE, Sennhauser FH. Posttraumatic stress impacts on quality of life in children after road traffic accidents: Prospective study. Aust. N. Z. J. Psychiatry 2009; 43: 746-53.

9 De Young A, Kenardy J. Posttraumatic stress disorder in young children. In: Tremblay RE, Boivin M, Peters RD, eds. Encyclopedia on Early Childhood Development. Montreal: Centre of Excellence for Early Childhood Development and Strategic Knowledge Cluster on Early Child Development, 2013; 1-6.

10 Marsac ML, Kassam-Adams N, Delahanty DL, Widaman KF, Barakat LP. Posttraumatic stress following acute medical trauma in children: $A$ proposed model of bio-psycho-social processes during the peritrauma period. Clin. Child. Fam. Psychol. Rev. 2014; 17: 399-411.

11 Horowitz L, Kassam-Adams N, Bergstein J. Mental health aspects of emergency medical services for children: Summary of a consensus conference. J. Pediatr. Psychol. 2001; 26: 491-502.

12 Marsac ML, Kassam-Adams N, Hildenbrand AK et al. Implementing a trauma-informed approach in pediatric health care networks. JAMA Pediatr. 2015; 170: 1-8.

13 Substance Abuse and Mental Health Services Administration. SAMHSA's Efforts to Address Trauma and Violence. Rockville, MD: The Administration, 2016. Available from: http://www.samhsa.gov/topics/traumaviolence/samhsas-trauma-informed-approach [accessed 1 December 2016].

14 Ko SJ, Ford JD, Kassam-Adams N et al. Creating trauma-informed systems: Child welfare, education, first responders, health care, juvenile justice. Prof. Psychol. Res. Pr. 2008; 39: 396.

15 Marsac M, Kassam-Adams N, Hildenbrand A, Kohser K, Winston FK. After the injury: Initial evaluation of a web-based intervention for parents of injured children. Health Educ. Res. 2011; 26: 1-12.

16 Banh MK, Saxe G, Mangione T, Horton NJ. Physician-reported practice of managing childhood posttraumatic stress in pediatric primary care. Gen. Hosp. Psychiatry 2008; 30: 536-45.

17 Kassam-Adams N, Rzucidlo S, Campbell $M$ et al. Nurses' views and current practice of trauma-informed pediatric nursing care. J. Pediatr. Nurs. 2015; 30: 478-84.

18 Ziegler MF, Greenwald MH, DeGuzman MA, Simon HK. Posttraumatic stress responses in children: Awareness and practice among a sample of pediatric emergency care providers. Pediatrics 2005; 115: 1261-7.

19 Alisic E, Hoysted C, Kassam-Adams N et al. Psychosocial care for injured children: Worldwide survey among hospital emergency department staff. J. Pediatr. 2016; 170: 227-33.

20 Jamieson J, Mitchell R, Le Fevre J, Perry A. The role of universities in Australasian emergency medicine training. Emerg. Med. Australas. 2015; 27: 257-60.

21 Hofman M, Sellei R, Peralta R et al. Trauma systems: Models of prehospital and inhospital care. Eur. J. Trauma Emerg. Surg. 2012; 38: 253-60.

22 The Trauma Recovery Lab. Measures. Melbourne: Trauma Recovery, 2017. Available from: http://www.trauma-recovery.net/over/ instruments/ [accessed 20 January 2017].

23 Babl F, Borland M, Ngo P et al. Paediatric Research in Emergency Departments International Collaborative (PREDICT): First steps towards the development of an Australian and New Zealand research network. Emerg. Med. Australas. 2006; 18: 143-7.

24 Klassen TP, Acworth J, Bialy L et al. Pediatric emergency research networks: A global initiative in pediatric emergency medicine. Pediatr. Emerg. Care 2010; 26: 541-3.

25 Alisic E, Zalta AK, van Wesel F et al. Rates of post-traumatic stress disorder in trauma-exposed children and adolescents: Meta-analysis. Br. J. Psychiatry 2014; 204: 335-40.

26 Kassam-Adams N, Bakker A, Marsac ML, Fein JA, Winston FK. Traumatic stress, depression, and recovery: Child and parent responses 
after emergency medical care for unintentional injury. Pediatr. Emerg. Care 2015; 31: 737-42.

27 Kassam-Adams N, Marsac ML, García-España JF, Winston F. Evaluating predictive screening for children's post-injury mental health: New data and a replication. Eur. J. Psychotraumatol. 2015; 6: 29313.

28 Brymer M, Layne C, Jacobs A et al. Psychological First Aid Field Operations Guide, 2nd edn. Los Angeles, CA: National Child Traumatic Stress Network and National Center for PTSD, 2006.

29 The National Child Traumatic Stress Network Learning Center. Psychological First Aid Online Course. Los Angeles, CA: The Learning Center for Child and Adolescent Trauma, 2015. Available from: http://learn.nctsn. org/course/index.php?categoryid=11 [accessed 10 December 2015].

30 Stuber ML, Schneider S, Kassam-Adams N, Kazak AE, Saxe G. The medical traumatic stress toolkit. CNS Spectr. 2006; 11: 137-42.

31 American Academy of Pediatrics. Trauma Toolbox for Primary Care. Washington, DC: The Academy, 2015. Available from: http://www.aap. org/en-us/advocacy-and-policy/aap-health-initiatives/healthy-fostercare-america/Pages/Trauma-Guide.aspx [accessed 10 December 2015].
32 Price DW, Wagner DP, Krane NK et al. What are the implications of implementation science for medical education? Med. Educ. Online 2015; 20 27003.

33 Johnston A, Abraham L, Greenslade J et al. Review article: Staff perception of the emergency department working environment: Integrative review of the literature. Emerg. Med. Australas. 2016; 28: 7-26.

34 Taylor DM, Pallant JF, Crook HD, Cameron PA. The psychological health of emergency physicians in Australasia. Emerg. Med. Australas. 2004; 16: 21-7.

\section{Supporting Information}

Additional Supporting Information may be found in the online version of this article at the publisher's web-site:

Appendix S1. A priori analyses.

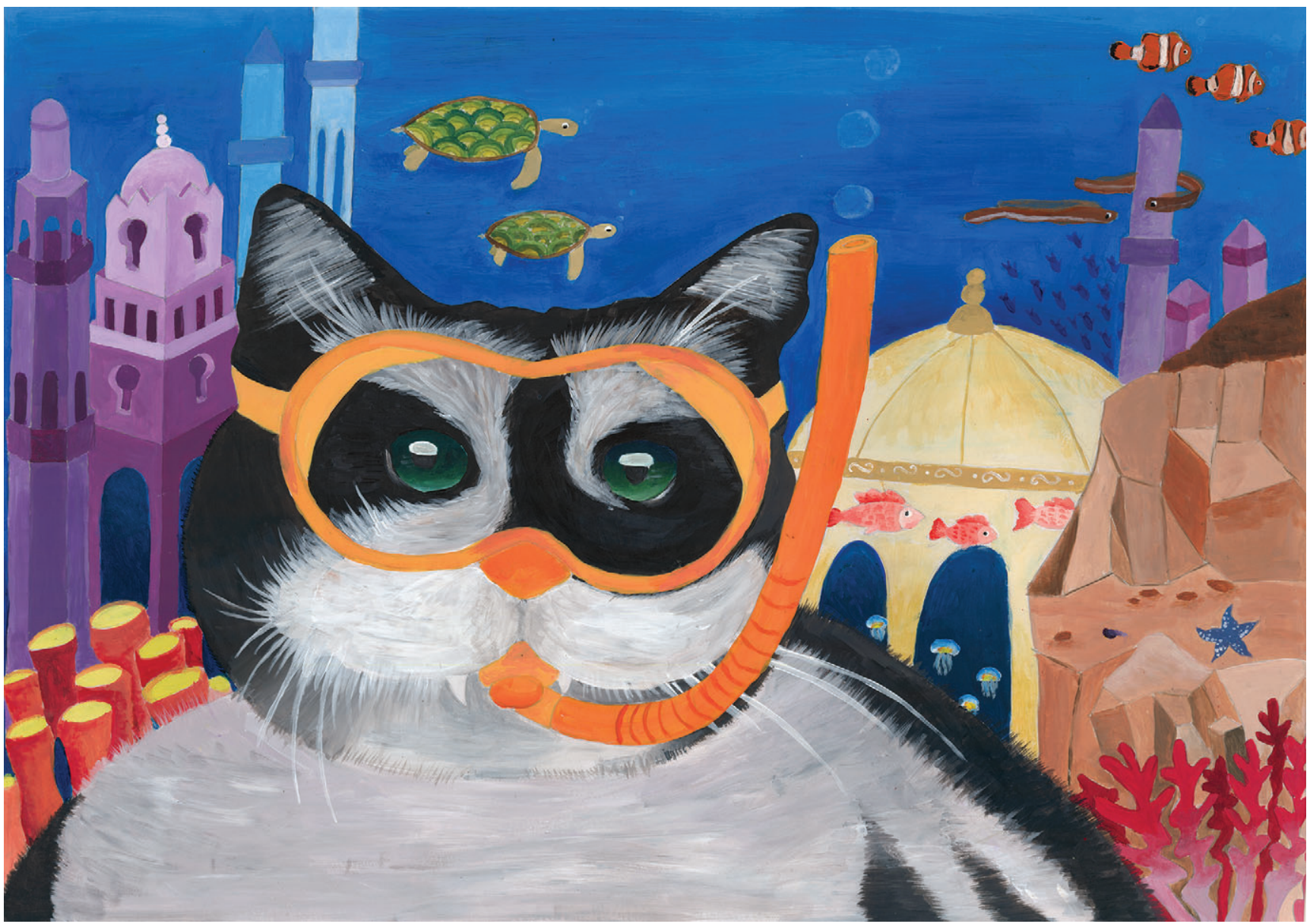

Underwater cat by Helen Hwang (age 15) from Operation Art 2016 